\section{Telling smokers their "lung age" promoted successful smoking cessation}

\section{STUDY DESIGN}

Design: randomised controlled trial.

Allocation: concealed. ${ }^{*}$

Blinding: blinded (outcome assessors). *

\section{STUDY QUESTION}

Setting: 5 general practices in Hertfordshire, UK.

Patients: 561 current smokers $\geqslant 35$ years of age (mean age 53 y, 54\% women, mean 17 cigarettes/day, mean 33 pack-years of smoking). Patients who were receiving oxygen or had a history of lung cancer, tuberculosis, asbestosis, silicosis, bronchiectasis, or pneumonectomy were excluded.

Intervention: all patients had spirometry at baseline to measure forced expiratory volume at 1 second $\left(\mathrm{FEV}_{1}\right)$. Patients in the intervention group $(\mathrm{n}=280)$ were immediately given their results verbally and graphically as "lung age" (age of the average healthy person who has an $\mathrm{FEV}_{1}$ equal to that of the patient); patients in the control group $(n=281)$ were not told their results at that time. Within 4 weeks, all patients received a letter from the study doctor giving test results (as lung age for the intervention group and as $\mathrm{FEV}_{1}[\mathrm{l} / \mathrm{s}]$ with no explanation for the control group), a strong statement about the importance of smoking cessation regardless of the test results, and contact details for smoking cessation services.
Outcomes smoking cessation (verified by saliva cotinine test) and daily cigarette consumption.

Follow-up period: 12 months.

Patient follow-up 89\% (intention-to-treat analysis).

\section{MAIN RESULTS}

At baseline, $27 \%$ of the intervention group and $23 \%$ of the control group had abnormal $\mathrm{FEV}_{1}(<80 \%$ of predicted). In the intervention group, mean lung age deficit (lung age minus actual age) was 9.3 years. Telling patients their lung age increased verified smoking cessation rate and reduced daily cigarette consumption (table).

\section{CONCLUSION}

Telling smokers their lung age after spirometry increased the likelihood of successful smoking cessation a year later.

*See glossary.

Abstract and commentary also appear in "ACP Journal Club: The Best Evidence for Patient Care" in Annals of Internal Medicine.

\section{ABSTRACTED FROM}

Parkes G, Greenhalgh T, Griffin M, et al. Effect on smoking quit rate of telling patients their lung age: the Step2quit randomised controlled trial. BMJ 2008;336:598-600.

Correspondence to: Dr G Parkes, The Limes Surgery, Hoddesdon, UK; parkesko@hotmail.co.uk

Source of funding: Health Foundation.

- Clinical impact ratings: GP/FP/Primary care 6/7; Respirology 6/7; Internal medicine $5 / 7$

Reporting spirometry results as "lung age" $v$ simple forced expiratory volume at 1 second $\left(\mathrm{FEV}_{1}\right)$ to promote smoking cessation*

\begin{tabular}{lllll}
\hline Outcomes at $\mathbf{1 2}$ months & $\begin{array}{l}\text { Results reported } \\
\text { as lung age }\end{array}$ & $\begin{array}{l}\text { Results reported } \\
\text { as FEV }\end{array}$ & RBI (95\% CI) & NNT (CI) \\
\hline Verified smoking cessation & $14 \%$ & $6.4 \%$ & $112 \%(25$ to 261) & 14 (9 to 45) \\
\hline & & & Difference in means (CI) & $-2.0(-3.8$ to -0.2$)$
\end{tabular}

${ }^{*}$ Abbreviations defined in glossary. $\mathrm{RBI}, \mathrm{NNT}$, and $\mathrm{Cl}$ calculated from data in article.

$\mathrm{P}$ arkes et al investigated personalised health assessment with normative feedback as a tool to promote smoking cessation. In this trial, smokers who received immediate, verbal information about their lung age were more likely to quit smoking than those who received undigested spirometry results.

In thinking about the generalisability of these results, one has to consider that spirometry is not readily available in many primary care practices. Further, spirometry results depend on patients' effort and cooperation, potentially limiting the reliability of results.

Despite these limitations to the practical implementation of spirometry in primary care, Parkes et al showed that the intervention did, in fact, improve quit rates. We do not know whether the key component was the additional counselling time (as part of verbal feedback), graphical presentation, lung-age concept, or something else about the entire intervention package. It is possible that this type of testingintensive assessment is no better at improving quit rates than estimating lung age from patients' smoking histories without spirometric testing and presenting it in a personalised, graphical manner.

Although this intervention was efficacious, its use alongside other smoking cessation tools is unclear: Should a busy clinician add spirometry, distribute free medications, or use a "fax to quit" programme with a Quitline?

The trial by Parkes et al provides 2 bottom-line messages. First, primary care clinicians should consider adding spirometry to routine practice with smokers as a way to increase motivation to quit. Second, if spirometry or other pulmonary function testing is performed, the way in which the results are conveyed to patients seems important. Given the improvement in quit rates, we suggest that the temporary standard (while awaiting further studies) should be to present the results in verbal and graphical forms made relevant to patients' lives, such as the lung-age concept.

Ellie Grossman, MD, MPH Scott Sherman, MD, MPH

New York University School of Medicine New York, New York, USA 